\title{
Differential patterns of evolution and distribution of the symbiotic behaviour in nostocacean cyanobacteria
}

Dimitra Papaefthimiou, ${ }^{1}$ Pavel Hrouzek, ${ }^{2,3,4}$ Maria Angela Mugnai, ${ }^{5,6}$ Alena Lukesova, ${ }^{7}$ Silvia Turicchia, ${ }^{5,8}$ Ulla Rasmussen ${ }^{1}$ and Stefano Ventura ${ }^{5}$

Correspondence Stefano Ventura stefano.ventura@ise.cnr.it

\footnotetext{
${ }^{1}$ Department of Botany, Stockholm University, S-10691 Stockholm, Sweden

${ }^{2}$ Department of Botany, Faculty of Biological Sciences, University of South Bohemia, České Budějovice, Czech Republic

${ }^{3}$ Institute of Physical Biology, University of South Bohemia, Nové Hrady, Czech Republic

${ }^{4}$ Institute of Microbiology, Department of Autotrophic Microorganisms, Academy of Sciences of the Czech Rrepublic, Opatovický Mlýn, Třeboň, Czech Republic

${ }^{5}$ Institute of Ecosystem Study, National Research Council of Italy, via Madonna del Piano 10, 50019 Sesto Fiorentino, Italy

${ }^{6} \mathrm{PhD}$ School in Science for Conservation of the Cultural Heritage, University of Florence, Italy

${ }^{7}$ Institute of Soil Biology, Biology Centre AS CR, v. v. i., Na Sádkách 7, 37005 České Budějovice, Czech Republic

${ }^{8} \mathrm{PhD}$ School in Polar Science, University of Siena, Italy
}

\begin{abstract}
Many cyanobacteria commonly identified as belonging to the genus Nostoc are well-known cyanobionts (symbionts) of a wide variety of plants and fungi. They form symbioses with bryophytes, pteridophytes, gymnosperms and angiosperms that are considerably different in the type of reciprocal interaction between the host and the cyanobiont. The phylogenetic and taxonomic relationships among cyanobionts isolated from different hosts and Nostoc strains isolated from free-living conditions are still not well understood. We compared phylogeny and morphology of symbiotic cyanobacteria originating from different host plants (genera Gunnera, Azolla, Cycas, Dioon, Encephalartos, Macrozamia and Anthoceros) with free-living Nostoc isolates originating from different habitats. After preliminary clustering with ARDRA (amplified rDNA restriction analysis), phylogeny was reconstructed on the basis of $16 \mathrm{~S}$ rRNA gene sequences and compared with morphological characterization, obtaining several supported clusters. Two main Nostoc clusters harboured almost all cyanobionts of Gunnera, Anthoceros and of several cycads, together with free-living strains of the species Nostoc muscorum, Nostoc calcicola, Nostoc edaphicum, Nostoc ellipsosporum and strains related to Nostoc commune. We suggest that the frequent occurrence of symbiotic strains within these clusters is explained by the intensive hormogonia production that was observed in many of the strains studied. However, no evidence for discrimination between symbiotic and free-living strains, either by molecular or morphological approaches, could be found. Sequences of Azolla cyanobiont filaments, taken directly from leaf cavities, clustered tightly with sequences from the planktic cyanobacterium Cylindrospermopsis raciborskii, from the benthic Anabaena cylindrica 133 and from Anabaena oscillarioides HINDAK 1984/43, with high bootstrap values. The phylogenetic analysis showed that two distinct patterns of evolution of symbiotic behaviour might exist for the nostocacean cyanobacteria, one leading to symbioses of Nostoc species with a wide variety of plants, the other leading to the association of a unique cyanobacterial type with the water fern Azolla.
\end{abstract}

Abbreviations: AKLC, akinete-like cells; ARDRA, amplified rDNA restriction analysis; ITS, internal transcribed spacer; ML, maximum-likelihood; MP, maximum-parsimony; NJ, neighbour-joining.

The GenBank/EMBL/DDBJ accession numbers for the 16S rRNA gene sequences determined in this study are AM711522-AM711554.

A supplementary figure showing the ARDRA of symbiotic and free-living cyanobacteria performed on the 16S rRNA gene +ITS region is available with the online version of this paper. 


\section{INTRODUCTION}

Filamentous cyanobacteria of the genus Nostoc are known to be the main symbiotic partners of a wide range of eukaryotic organisms, where the hosts are found among all kingdoms: protists, animals, fungi and plants (Rai et al., 2002). According to the International Code of Botanical Nomenclature, the genus Nostoc belongs to the order Nostocales and, in Bergey's Manual of Systematic Bacteriology, it is affiliated to subsection IV of Cyanobacteria (Rippka et al., 2001). In recent phylogenetic studies, using several molecular marker genes (small subunit rRNA, $r p o B, r b c L X$ and nifD or nifH), the closest relatives to the genus Nostoc were shown to be the genera Anabaena, Aphanizomenon and Trichormus, also members of the family Nostocaceae (Rajaniemi et al., 2005; Svenning et al., 2005; Henson et al., 2002, 2004; Lohtander et al., 2003). All members of the genus Nostoc are characterized by a complex life cycle that includes differentiation into heterocytes (nitrogen-fixing cells), akinetes (resting spores) and hormogonia (motile filaments), serving for dispersion and as infective units in symbiosis (Lazaroff, 1966; Lazaroff \& Vishniac, 1961; Mollenhauer, 1970; Rippka et al., 1979). Four Nostoc groups, three of which corresponded to the type species Nostoc muscorum, Nostoc edaphicum and Nostoc calcicola, have been resolved on the basis of their life cycle (Hrouzek et al., 2003; Rajaniemi et al., 2005) but, following the analysis of 81 additional 16S rRNA gene sequences of cyanobacterial strains identified as belonging to the genus Nostoc, many more clusters were obtained. These clusters were separated to an extent, indicating that they might represent different taxa (Hrouzek et al., 2005).

The symbiotic relationships of nostocacean cyanobacteria with the plant kingdom involve plants from the divisions Bryophyta (mosses, liverworts and hornworts), Pteridophyta (the genus Azolla), gymnosperms (family Cycadaceae) and angiosperms (family Gunneraceae). Identification and diversity studies of the cyanobionts from the individual plant hosts, with the exception of Azolla, have revealed high strain diversity both within and among different host species (Rasmussen \& Svenning, 1998; Nilsson et al., 2000; Guevara et al., 2002; Zheng et al., 2002; West \& Adams, 1997; Costa et al., 2001; Rasmussen \& Nilsson, 2002). Among the cyanobacteria associated with cycads, the species N. muscorum and Nostoc punctiforme have been identified (Costa et al., 1999).

The symbiosis with the water fern Azolla is well studied, mainly due to the potential use of Azolla as a fertilizer in rice fields (Van Hove \& Lejeune, 2002), and also for its unique perpetual nature (Lechno-Yossef \& NierzwickiBauer, 2002). The Azolla cyanobionts, together with symbionts belonging to other bacterial phyla, are hosted within specialized cavities in the fern leaves (Lechno-Yossef \& Nierzwicki-Bauer, 2002). Originally, the cyanobionts of Azolla were described as Anabaena azollae by Strasburger (1884). However, morphological studies of the cyanobacterial populations inhabiting the cavity, performed on presumed cultivated cyanobionts, yielded misleading or incomplete results on the taxonomic position of the cyanobionts (Gebhardt \& Nierzwicki-Bauer, 1991). Comparative molecular studies have revealed that cultured cyanobacteria isolated from the fern were indeed different from the cyanobiont population inhabiting the leaf cavity, leading to the suggestion that one major cyanobacterial population is involved in the symbiosis, while other minor populations are non-specifically associated with the fern (Tomaselli et al., 1988; Plazinski et al., 1990; Gebhardt \& Nierzwicki-Bauer, 1991; Pabby et al., 2003). Up to now the taxonomy of the cyanobacterial populations living inside the leaf cavity of Azolla remains undefined and largely controversial. What is well accepted is that these cyanobionts belong to the order Nostocales, while there is a continuous debate on whether they belong to Nostoc (Plazinski et al., 1990; Gebhardt \& Nierzwicki-Bauer, 1991; Pabby et al., 2003), Anabaena (Gebhardt \& NierzwickiBauer, 1991; Svenning et al., 2005) or Trichormus (Komárek \& Anagnostidis, 1989), or if they constitute a separate genus (Caudales et al., 1995; Baker et al., 2003).

The aim of the present study was to use an integrated morphological and molecular approach for a comparative analysis of nostocacean cyanobacteria of symbiotic origin, including strains isolated from the angiosperm Gunnera, the gymnosperm cycads, the bryophyte Anthoceros and cyanobionts of the water fern Azolla, as well as cyanobacterial strains of free-living origins. The molecular tools employed in the present study, amplified rDNA restriction analysis (ARDRA) of the 16S rDNA + ITS (internal transcribed spacer) and phylogenetic analysis of the $16 \mathrm{~S}$ rRNA gene, provided evidence of high genetic diversity among the cyanobacteria studied that was strongly supported by morphological analysis.

\section{METHODS}

Cyanobacterial strains and Azolla cyanobionts. We studied 28 cyanobacterial strains previously assigned to the genus Nostoc, and three cyanobiont populations directly extracted from the leaf cavity of plants belonging to three distinct species of Azolla (Table 1). Symbiotic Nostoc strains were isolated from the following host plants: seven strains from species of the angiosperm genus Gunnera, four strains from cycads and two from the genus Anthoceros. Fifteen cyanobacterial strains isolated from free-living conditions were also included in the study. Details of species and origins of the host plants, origins of cultures and references to original descriptions, are given in Table 1. For molecular analysis, free-living and symbiotic Nostoc strains were grown in nitrogen-free BG-11 medium (Rippka et al., $1979)$ in continuous light $\left(80 \mu \mathrm{mol}\right.$ photons $\mathrm{m}^{-2} \mathrm{~s}^{-1}$ intensity) with gentle shaking, at $28{ }^{\circ} \mathrm{C}$. For morphological studies, the individual strains were transferred to $1.5 \% \mathrm{w} / \mathrm{v}$ agar plates and kept at a temperature of $20 \pm 2{ }^{\circ} \mathrm{C}$ and light intensity of $35 \mu \mathrm{mol}$ photons $\mathrm{m}^{-2}$ $\mathrm{s}^{-1}$, until examined. Cyanobionts from Azolla were directly collected from the host plants Azolla pinnata subsp. pinnata strain 7001, Azolla rubra strain ADUL2 and Azolla caroliniana strain 3001 grown in freshwater in the greenhouse at Stockholm University. Mature fronds of each strain of Azolla were collected, washed several times with distilled water and the roots were removed. The 'gentle roller' 
Table 1. Cyanobacterial strains included in this study, their origin and references to literature and to GenBank/EMBL/DDBJ sequence accession numbers

The accession numbers of strains for which the $16 \mathrm{~S}$ rRNA gene sequence has been determined in this work are in bold.

\begin{tabular}{|c|c|c|c|}
\hline Classification & Strain & Host or habitat, location & Reference (accession no.) \\
\hline Nostoc sp. & $\mathrm{All}^{*}$ & Anthoceros laevis (Bryophyta), Naples, Italy & Vagnoli et al. (1992) (AM711522) \\
\hline Nostoc sp. & $\mathrm{Al}^{*}$ & Anthoceros laevis (Bryophyta), Lucca, Italy & Vagnoli et al. (1992) (AM711531) \\
\hline Nostoc sp. & $\mathrm{De}^{*}$ & Dioon edule (Gymnospermae), Rome, Italy & Vagnoli et al. (1992) (AM711534) \\
\hline Nostoc sp. & $\mathrm{Cr}^{*}$ & Cycas revoluta (Gymnospermae), Florence, Italy & Vagnoli et al. (1992) (AM711533) \\
\hline Nostoc sp. & $\mathrm{Gm}^{*}$ & Gunnera manicata (Angiospermae), Siena, Italy & Vagnoli et al. (1992) (AM711536) \\
\hline Nostoc sp. & $0 \mathrm{GU} 36 \mathrm{~S} 01^{*}$ & Gunnera tinctoria (Angiospermae), Achill Island, Ireland & Not available (AM711526) \\
\hline Nostoc sp. & $0 \mathrm{GU} 36 \mathrm{~S} 02^{*}$ & Gunnera tinctoria (Angiospermae), Achill Island, Ireland & Not available (AM711527) \\
\hline Azolla symbiont & 7001 & Azolla pinnata subsp. pinnata 7001, Australia & Zheng et al. (1999) (AM711551) \\
\hline Azolla symbiont & ADUL2* & Azolla rubra ADUL2, New Zealand & Zheng et al. (1999) (AM711550) \\
\hline Nostoc sp. & $8901: 1 \dagger$ & Gunnera macrophylla (Angiospermae), New Zealand & Nilsson et al. (2000) (AM711539) \\
\hline Nostoc sp. & $8964: 3 \dagger$ & Gunnera prorepens (Angiospermae), New Zealand & Nilsson et al. (2000) (AM711541) \\
\hline Nostoc sp. & Lukesova $1 / 86 \ddagger$ & Oak forest mineral soil layer, Netolice, Czech Republic & Hrouzek et al. (2005) (AM711545) \\
\hline Nostoc sp. & Lukesova $40 / 93 \ddagger$ & $\begin{array}{l}\text { Alluvial soil on granite and dolomite rocks, Ellesmere, } \\
\text { Canada }\end{array}$ & Hrouzek et al. (2005) (AM711528) \\
\hline Nostoc sp. & Lukesova $5 / 96 \ddagger$ & $\begin{array}{l}\text { Clay soil, dump after coal mining, Sokolov, Czech } \\
\text { Republic }\end{array}$ & Hrouzek et al. (2005) (AM711546) \\
\hline Nostoc muscorum & Lukesova $1 / 87 \ddagger$ & Soil, wet meadow, Dlouha Ves, Czech Republic & Not available (AM711523) \\
\hline Nostoc muscorum & Lukesova $2 / 91 \ddagger$ & Arable field, Nezamyslice, Czech Republic & Hrouzek et al. (2005) (AM711524) \\
\hline Nostoc sp. & $\mathrm{TO}_{\mathrm{S} 01}^{*}$ & Woodland, Tuscany, Italy & Not available (AM711549) \\
\hline Nostoc sp. & TH1S01* & Rice field not flooded by water, Thailand & Not available (AM711547) \\
\hline Nostoc sp. & PCC $9231 \S$ & Gunnera dentata (Angiospermae), New Zealand & Svenning et al. (2005) (AY742452) \\
\hline Nostoc sp. & PCC 9229\$ & Gunnera monoica (Angiospermae), New Zealand & Svenning et al. (2005) (AY742451) \\
\hline Nostoc sp. & PCC $73102 \$$ & Macrozamia sp. (Gymnospermae), Australia & Rippka \& Herdman (1992) (AF027655) \\
\hline Nostoc sp. & PCC $7120 \$$ & Iowa State University, Iowa, USA & Rippka \& Herdman (1992) (NC_003272) \\
\hline Nostoc sp. & PCC9305\$ & Anthoceros punctatus (Bryophyta), California, USA & Svenning et al. (2005) (AY742453) \\
\hline Nostoc sp. & $8938 \dagger$ & Gunnera dentata (Angiospermae), New Zealand & Svenning et al. (2005) (AY742454) \\
\hline Nostoc sp. & $8941 \dagger$ & Gunnera dentata (Angiospermae), New Zealand & Svenning et al. (2005) (AY742448) \\
\hline Nostoc sp. & $8916 \dagger$ & Gunnera monoica (Angiospermae), New Zealand & Svenning et al. (2005) (AY742447) \\
\hline Nostoc sp. & $8963 \dagger$ & Gunnera prorepens (Angiospermae), New Zealand & Svenning et al. (2005) (AY742449) \\
\hline Nostoc sp. $\dagger$ & & Azolla filiculoides 1010, Peru & Svenning et al. (2005) (AY742450) \\
\hline $\begin{array}{l}\text { Anabaena } \\
\text { oscillarioides }\end{array}$ & HINDAK 1984/43 & Canada & Rajaniemi et al. (2005) (AJ630428) \\
\hline $\begin{array}{l}\text { Anabaena cf. } \\
\text { cylindrica }\end{array}$ & XP6B & Sediment, Gulf of Finland, Porkkala, Finland & Rajaniemi et al. (2005) (AJ630414) \\
\hline $\begin{array}{l}\text { Anabaena } \\
\text { planctonica }\end{array}$ & 1TU36S8 & Lake Tuusulanjärvi, Finland & Rajaniemi et al. (2005) (AJ630433) \\
\hline $\begin{array}{l}\text { Anabaena } \\
\text { oscillarioides }\end{array}$ & BECID32 & Epilithic, Gulf of Finland, Vousaari, Finland & Rajaniemi et al. (2005) (AJ630427) \\
\hline
\end{tabular}


Table 1. cont.

\begin{tabular}{|c|c|c|c|}
\hline Classification & Strain & Host or habitat, location & Reference (accession no.) \\
\hline $\begin{array}{l}\text { Trichormus } \\
\text { variabilis }\end{array}$ & HINDAK 2001/4 & Soil, Dombay Valley, Caucasus Mountains, Russia & Rajaniemi et al. (2005) (AJ630456) \\
\hline Trichormus azollae & KOM BAI/1983 & India & Rajaniemi et al. (2005) (AJ630454) \\
\hline Nostoc sp. & 1TU14S8 & Lake Tuusulanjärvi, Finland & Rajaniemi et al. (2005) (AJ630453) \\
\hline $\begin{array}{l}\text { Anabaena } \\
\text { augstumalis }\end{array}$ & JAHNKE/4a & Rostock, Germany & Rajaniemi et al. (2005) (AJ630458) \\
\hline $\begin{array}{l}\text { Anabaena cf. } \\
\text { cylindrica }\end{array}$ & 133 & Lake Arresø, Denmark & Gugger et al. (2002) (AJ293110) \\
\hline Nostoc muscorum & CENA 18 & Wetland sediment, Japurà River, Amazon basin, Brazil & Fiore et al. (2005) (AY218827) \\
\hline Nostoc calcicola & $\begin{array}{l}\text { III (Lukesova } \\
\text { 9/89) } \ddagger\end{array}$ & Field, České Budějovice, Czech Republic & Rajaniemi et al. (2005) (AJ630447) \\
\hline Nostoc edaphicum & $\begin{array}{l}\text { X (Lukesova } \\
11 / 88) \ddagger\end{array}$ & Field, Chelcice, Czech Republic & Rajaniemi et al. (2005) (AJ630449) \\
\hline $\begin{array}{l}\text { Nostoc } \\
\text { ellipsosporum }\end{array}$ & $\begin{array}{l}\text { V (Lukesova } \\
51 / 91) \ddagger\end{array}$ & Field, Nezamyslice, Czech Republic & Rajaniemi et al. (2005) (AJ630450) \\
\hline Nostoc muscorum & $\begin{array}{l}\text { I (Lukesova } \\
\text { 14/86) }\end{array}$ & Field, Dlouha Ves, Czech Republic & Rajaniemi et al. (2005) (AJ630451) \\
\hline $\begin{array}{l}\text { Nodularia } \\
\text { harveyana }\end{array}$ & Lukesova $18 / 94 \ddagger$ & Saline meadow, Sedlec, Czech Republic & Not available (AM711554) \\
\hline Nodularia sp. & Lukesova $1 / 91 \ddagger$ & Salty sand, oil mining area, West Siberia, Russia & Not available (AM711553) \\
\hline $\begin{array}{l}\text { Cylindrospermopsis } \\
\text { raciborskii }\end{array}$ & Solomon Dam & & (AF067819) \\
\hline $\begin{array}{l}\text { Cylindrospermopsis } \\
\text { raciborskii }\end{array}$ & AWT205 & & $(\mathrm{AF} 092504)$ \\
\hline $\begin{array}{l}\text { Chroococcidiopsis } \\
\text { thermalis }\end{array}$ & PCC 7203 & & Rippka \& Herdman (1992) (AB039005) \\
\hline
\end{tabular}

${ }^{\star}$ Strains kept in the CNR-CCC, the Cyanobacterial Culture Collection of the CNR - Institute for Ecosystem Study, Sesto Fiorentino, Italy. $\dagger$ Strains kept in the Culture Collection of the Department of Botany, Stockholm University, Sweden.

¥Strains kept in the Culture Collection of Soil Algae and Cyanobacteria of the Institute of Soil Biology, České Budějovice, Czech Republic. $\$$ Strains kept in the PCC (Pasteur Culture Collection of Cyanobacteria), Institut Pasteur, Paris, France.

procedure (Peters \& Mayne, 1974) was utilized to isolate filaments of symbiotic cyanobacteria from within leaf cavities.

DNA extraction. DNA was extracted from biomass of freshly grown cyanobacterial cultures and from filament bundles isolated from Azolla leaves as described by Hrouzek et al. (2005). After ethanol precipitation, DNA was resuspended in 50 or $100 \mu \mathrm{l}$ TE buffer (10 mM Tris/ $\mathrm{HCl} \mathrm{pH} 7.5,1 \mathrm{mM}$ EDTA) and stored at $-20{ }^{\circ} \mathrm{C}$.

Amplification of the 16S rRNA gene+ITS. All cultures of the cyanobacterial strains studied were unialgal, but several of them were not axenic. Therefore, a cyanobacteria-specific protocol was used for the amplification of the 16S rRNA gene + ITS region, using primers $16 \mathrm{~S} 27 \mathrm{~F}$ and $23 \mathrm{~S} 30 \mathrm{R}$, the latter being specific for cyanobacteria (Taton et al., 2003). The $50 \mu \mathrm{l} \mathrm{PCR}$ volume contained $1 \mu \mathrm{l}$ DyNAzyme EXT $\left(1 \mathrm{U}^{-1} \mathrm{l}^{-1}\right.$ ) (Finnzymes), $5 \mu \mathrm{l} 10 \times$ DyNAzyme EXT buffer containing $50 \mathrm{mM} \mathrm{MgCl} 2,5 \mu \mathrm{dNTP}$ mixture containing $2 \mathrm{mM}$ concentration of each dNTP, $2.5 \mu \mathrm{l}\left(10 \mathrm{pmol} \mu \mathrm{l}^{-1}\right)$ of each primer and $5 \mu \mathrm{l}$ BSA $\left(10 \mathrm{mg} \mathrm{ml}^{-1}\right)$. The mixture was sterilized under UV light and $1 \mu \mathrm{l}$ DNA template was added for amplification to take place according to the following PCR program: $94{ }^{\circ} \mathrm{C}$ for $5 \mathrm{~min}, 10$ cycles of $94{ }^{\circ} \mathrm{C}$ for $45 \mathrm{~s}, 57^{\circ} \mathrm{C}$ for $45 \mathrm{~s}$ and $2 \mathrm{~min}$ at $72{ }^{\circ} \mathrm{C}, 25$ cycles of $94{ }^{\circ} \mathrm{C}$ for $45 \mathrm{~s}$, $54{ }^{\circ} \mathrm{C}$ at $45 \mathrm{~s}$ and $2 \mathrm{~min}$ at $72{ }^{\circ} \mathrm{C}$, and extension at $72{ }^{\circ} \mathrm{C}$ for $7 \mathrm{~min}$. PCR products were checked on $1 \% \mathrm{w} / \mathrm{v}$ agarose gel.

Fingerprint analysis (ARDRA). The PCR products (approx. $2 \mathrm{kbp}$ ) were digested separately with restriction endonucleases MboI, HpaII and HhaI (Fermentas). Digestions were carried out according to the manufacturer's instructions in $10 \mu \mathrm{l}$ total volume. The restriction fragments obtained were separated on a $2.8 \% \mathrm{w} / \mathrm{v}$ MetaPhor agarose gel (Lonza) for $4.5 \mathrm{~h}$ at $150 \mathrm{~V}$ and $15{ }^{\circ} \mathrm{C}$. Analysis of electrophoretic profiles was carried out on digital images using the software BioNumerics version 2.5 (Applied Maths). For each strain, a composite profile obtained by assembling three normalized restriction profiles, one for each restriction endonuclease, was included in the analysis. DNA molecular weight marker XIV (Roche) was run in several positions of each gel for electrophoretic profile normalization. Gel profiles were manually edited to check for the correct assignment of the bands to band classes. The unweighted pair-group method using arithmetic averages (UPGMA) was performed on the normalized composite profiles. Fragments shorter than $100 \mathrm{bp}$ were not considered in the analysis.

Sequencing and analysis of the 16S rRNA. Aliquots of PCR products from the 16S rRNA gene + ITS region were sent for fulllength sequencing to Cogenics (Grenoble, France). Sequencing primers were 16S979F, 16S544R and 16S1092R (Hrouzek et al., 2005). The chromatograms were analysed by the gauntlet PHRED/ PHRAP/CONSED (Gordon, 2004) and consensus sequences imported in ARB (Ludwig et al., 2004), which was used for all subsequent analytical steps. Sequences were aligned with the ARB database of public domain sequences and trimmed at a position homologous to the end of the Escherichia coli $16 \mathrm{~S}$ rRNA gene sequence. The alignment was used to generate phylogenetic trees based on three different algorithm options 
integrated in ARB: neighbour-joining (NJ), maximum-parsimony (MP) and maximum-likelihood (ML). A selection of publicly available sequences belonging to the genera Anabaena, Cylindrospermopsis, Nodularia, Nostoc and Trichormus (Table 1) was added to the sequences of the strains studied in this work; Chroococcidiopsis thermalis PCC 7203 was used to root all trees. NJ and MP analysis were bootstrapped with 500 and 100 replicates, respectively; due to software constraints, ML analysis was not subjected to bootstrap.

Morphological study. The morphological study was performed on a total of 17 cultured strains (Table 2), including ten symbiotic and seven free-living ones. All examinations were performed on cultures growing on agar plates. In addition, basic morphometric measurements were performed on three Azolla cyanobionts, which were directly mounted on slides after collection from the leaf cavity; the observation of such natural samples did not allow the evaluation of hormogonia formation and life cycle changes. Morphology of the isolates was studied in young, exponentially growing and old cultures of 3,10 and 30 days, respectively. Cyanobacteria were examined under an Olympus CX40 light microscope equipped with a digital camera. The morphology of colonies, vegetative filaments, hormogonia and of the mucilaginous sheaths of filaments and the different cell types (vegetative cells, heterocytes and akinetes) were studied. Cell parameters were measured using the DP-SOFT software (Olympus); 50-300 measurements were taken for each parameter to describe the trait variability. Vegetative filaments and hormogonia were classified according to their length and shape into the following categories: long filaments ( $>50$ vegetative cells), short filaments $(<50$ vegetative cells), coiled, wavy or straight filaments. The morphology of the mucilaginous sheaths was classified into two main categories: diffusive (where no sharp edges of microcolony could be observed) and enveloping filament (delicate, not laminated sheath expanding 2 $5 \mu \mathrm{m}$ around the filament). The collected data were analysed with the software Statistica for Windows (StatSoft). Cluster analysis was carried out for similarities in selected morphological characters of studied strains [width of filaments, presence of akinete-like cells (AKLC), length of filament and proportion of terminal cells] by using the same software. Morphological data previously obtained following the same protocol (Hrouzek et al., 2005) were included in the cluster analysis. To calculate distances in the cluster analysis, the Euclidean distance and complete linkage parameters were used.

\section{RESULTS AND DISCUSSION}

\section{Phenotypic analysis}

To allow for a wider account of Nostoc morphology, data obtained in this work were considered along with data from 14 other free-living and symbiotic Nostoc strains described by Hrouzek et al. (2005). In all seven studied isolates from Gunnera, the apoheterocytic formation of akinetes and the formation of motile hormogonia observed corresponded with recent descriptions of the development and the morphological structures of the genera Nostoc or Trichormus (Komárek \& Anagnostidis, 1989; Rippka et al., 1979). However, their morphometric evaluation showed a remarkable degree of heterogeneity in several characters. Data are summarized in Table 2 and Figs 1-3.

Table 2. Morphological features of cyanobacterial strains included in this study

TH, Shape of terminal heterocyte; Horm., presence of hormogonia; AKLC, presence of akinete-like cells; Fattened, fattened cells similar to AKLC; ND, not determined. Dimensions given as length $\times$ width: max.(mean)min.

\begin{tabular}{|c|c|c|c|c|c|c|c|c|}
\hline \multirow[t]{2}{*}{ Genus } & \multirow[t]{2}{*}{ Strain } & \multicolumn{2}{|c|}{ Dimensions $(\mu \mathrm{m})$} & \multirow[t]{2}{*}{ TH } & \multirow{2}{*}{$\begin{array}{l}\text { Shape of } \\
\text { filaments }\end{array}$} & \multirow[t]{2}{*}{ Horm. } & \multirow[t]{2}{*}{ AKLC } & \multirow{2}{*}{$\begin{array}{c}\text { Mucilaginous } \\
\text { envelope }\end{array}$} \\
\hline & & Vegetative cells & Akinetes & & & & & \\
\hline Nostoc sp. & De1 & $6.3(4.0) 2.3 \times 5.4(4.4) 3.4$ & $8.0(7.0) 5.9 \times 4.9(4.3) 3.6$ & Oval & Long wavy & + & - & Diffusive \\
\hline Nostoc sp. & $\mathrm{Cr} 4$ & $8.2(5.5) 3.2 \times 5.4(4.4) 3.3$ & $9.5(6.4) 3.7 \times 6.2(5.1) 3.8$ & Oval & Long wavy & + & - & Diffusive \\
\hline Nostoc sp. & $\mathrm{Gm}$ & $7.5(4.6) 3.0 \times 4.1(2.9) 1.8$ & $7.4(6.7) 5.9 \times 3.8(3.7) 3.6$ & Oval & Long wavy & + & + & Diffusive \\
\hline Nostoc sp. & $8964: 3$ & $6.8(4.1) 1.8 \times 7.0(4.5) 2.8$ & $8.2(6.0) 4.3 \times 5.6(4.8) 3.8$ & No & Long wavy & - & - & Diffusive \\
\hline Nostoc muscorum & $\begin{array}{l}\text { Lukešová } \\
1 / 87\end{array}$ & $7.3(4.6) 2.9 \times 5.8(4.5) 3.5$ & $8.1(6.4) 4.5 \times 6.3(5.0) 3.9$ & No & Long wavy & + & - & Diffusive \\
\hline Nostoc sp. & T01S01 & $7.6(5.0) 2.9 \times 4.1(3.4) 2.7$ & $8.4(\mathbf{8 . 2}) 8.1 \times 4.8(\mathbf{4 . 6}) 4.4$ & Conic & Long wavy & + & - & Diffusive \\
\hline Nostoc sp. & TH1S01 & $6.9(4.9) 3.3 \times 5.9(5.0) 3.9$ & $7.8(5.8) 4.3 \times 6.3(5.3) 4.5$ & Oval & Long wavy & - & - & Diffusive \\
\hline Nostoc sp. & 0GU36S02 & $6.6(4.3) 2.9 \times 4.5(3.5) 2.4$ & $7.3(6.6) 5.1 \times 7.0(5.1) 3.9$ & Conic & Irreg. coiled & + & + & Enveloping \\
\hline Nostoc sp. & 8926 & $8.6(5.4) 3.1 \times 4.3(3.6) 2.9$ & $7.9(7.3) 6.1 \times 4.5(4.1) 3.8$ & Conic & Short wavy & + & + & Enveloping \\
\hline Nostoc sp. & 996 & $5.1(3.1) 1.7 \times 4.1(2.8) 1.9$ & $6.7(5.4) 4.4 \times 3.8(3.4) 3.1$ & Oval & Irreg. coiled & - & - & Firm \\
\hline Azolla symbiont & 7001 & $15.0(\mathbf{1 0 . 8}) 5.5 \times 11.5(\mathbf{8 . 9}) 6.6$ & ND & No & Long wavy & ND & - & ND \\
\hline Azolla symbiont & ADUL2 & $15.2(8.7) 5.1 \times 7.5(6.1) 4.6$ & ND & No & Long wavy & ND & - & $\mathrm{ND}$ \\
\hline Azolla symbiont & 3001 & $18.9(8.7) 5.5 \times 7.6(5.9) 4.7$ & ND & No & Long wavy & ND & - & $\mathrm{ND}$ \\
\hline
\end{tabular}




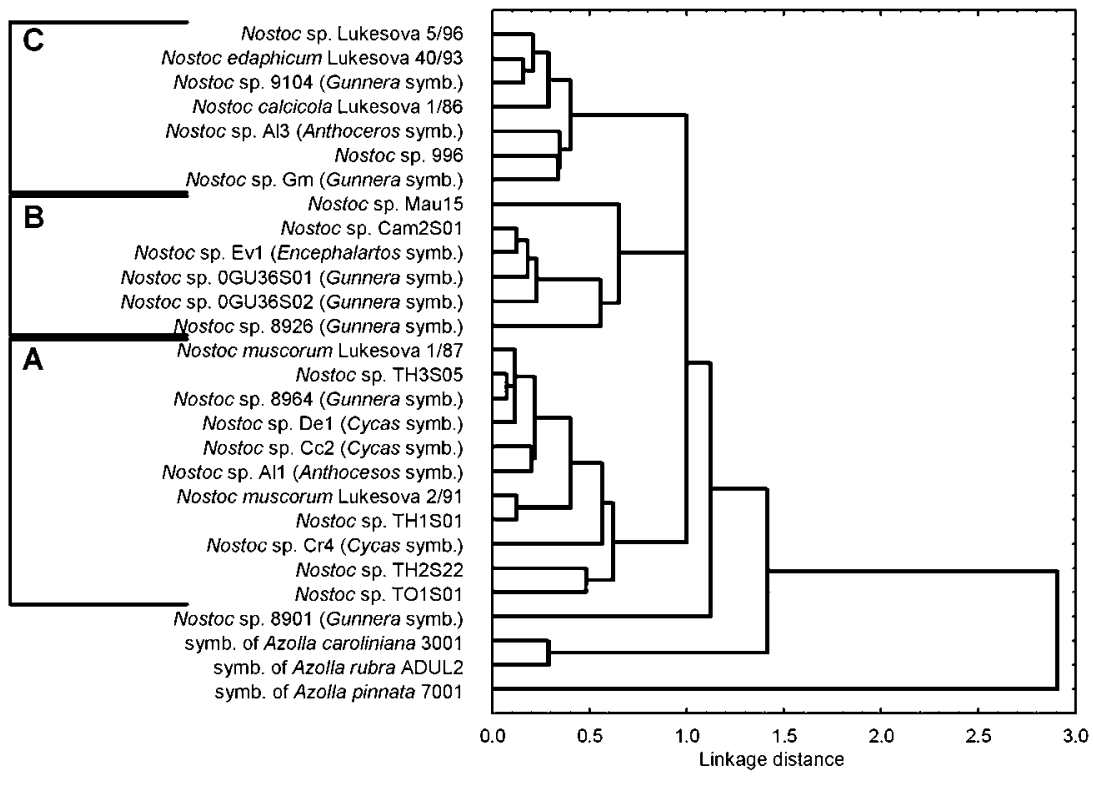

Fig. 1. Cluster analysis of selected morphological data of symbiotic and free-living cyanobacterial strains performed with the method of single linkage, Euclidean distance. Width of filaments, presence of AKLC, length of filaments and proportion of terminal cells were taken into consideration. Morphological data relative to strains Lukesova 5/96, 40/93, 1/86, 2/91, Al3, Mau15, Ev1, TH3SO5, Cc2 and TH2S22 had been obtained previously (Hrouzek et al., 2005). symb., symbiont.
Under the cultivation conditions applied, hormogonia could be observed in all but two symbiotic Nostoc strains: Gunnera cyanobionts 8901:1 and 8964:3 (Table 2 and Hrouzek et al., 2005). The cyanobacterial strains Nostoc sp. 8926 (isolated from Gunnera hamiltonii), OGU36S01, OGU36S02 and 9104 (isolated from Gunnera tinctoria) and $\mathrm{Gm}$ (isolated from Gunnera manicata) showed abundant formation of typical straight hormogonia with conical end-cells (Fig. 2d, f); formation of akinete-like cells (AKLC) was also observed (Fig. 2e, p). However, strains $8964: 3$ and $8901: 1$, isolated from Gunnera prorepens and Gunnera macrophylla, respectively, showed a clearly distinct morphology, forming long vegetative filaments consisting of oval cells embedded in diffusive mucilage (Fig. 2a-c). Moreover, no hormogonia were observed and AKLC were completely missing from strain $8964: 3$, while atypical fattened cells, similar to AKLC, were observed in strain $8901: 1$. Granulated akinetes in long chains appeared during the differentiation of the filaments. Such morphology is typical of the N. muscorum group as defined by Hrouzek et al. (2005). The division of Nostoc strains on the basis of the morphological characters observed is supported by the cluster analysis of selected morphological data shown in Fig. 1 (width of filaments, presence of AKLC, length of filaments and proportion of terminal cells were taken into consideration). For this cluster analysis, previously obtained morphometric data were also used (Hrouzek et al., 2005).

Apart from the Azolla cyanobionts and the Gunnera symbiont strain $8901: 1$, which were situated at the base of the UPGMA dendrogram of morphological data, three main branches could be seen in the cluster analysis shown in Fig. 1. Mainly strains with long vegetative filaments, clearly defined granulated akinetes (Fig. 2b) and hormogonia similar to vegetative filaments were located in branch A. Except for Gunnera strain 8964 : 3, symbionts of cycads strains De and Cr4 (Fig. 2m-o), Anthoceros symbiont strain All (Fig. 2h) and the free-living strains TH1SO1 (Fig. 3a) and $\mathrm{TH} 3 \mathrm{SO} 5$ were also members of this branch. This morphological group also included the free-living N. muscorum strains Lukesova $1 / 87$ and 2/91 (Fig. 2c) and the cycad symbiont strain $\mathrm{Cc} 2$, which had been characterized previously (Hrouzek et al., 2005). Branches B and C contained most of the Gunnera symbionts included in the present study: strains 9104 (Fig. 2f), 8926 (Fig. 2d, e), Gm (Fig. 2l), OGU36S01 (Fig. 2p) and OGU36S02. These groups corresponded to the morphological group of $N$. calcicola.

Despite the identification of common characters, the group of $N$. calcicola is still very heterogeneous, as demonstrated by the fact that strains similar to N. calcicola were separated into two clusters, B and C.

Strains characterized by microcolony formation (Nostoc sp. 996, Lukesova 5/96 and 40/93), a character not included in the calculation of the dendrogram, were present in group $\mathrm{C}$ and strains growing in thin films (N. calcicola Lukesova 1/ 86, TH2S22, TO1SO1 and Mau15) were present in all clusters. In two of the film-forming strains (TH2S22 and TH3SO5), similarity to the Trichormus description is evident, which can be distinguished from Nostoc solely by the thin-film growth (Komárek \& Anagnostidis, 1989).

Morphological analysis of the cyanobionts from the Azolla leaf cavities was performed on cyanobacterial filaments collected directly from the leaf cavity, since the cyanobionts are uncultivable (Lechno-Yossef \& Nierzwicki-Bauer, 2002). Filaments consisted of significantly wider cells (8$15 \mu \mathrm{m}$ ) than those observed in all other strains studied. The cell enlargement could be a consequence of the symbiotic condition (Rai et al., 2000), and thus the measured dimensions cannot be considered necessarily stable in hypothetical in vitro cultivation conditions. 


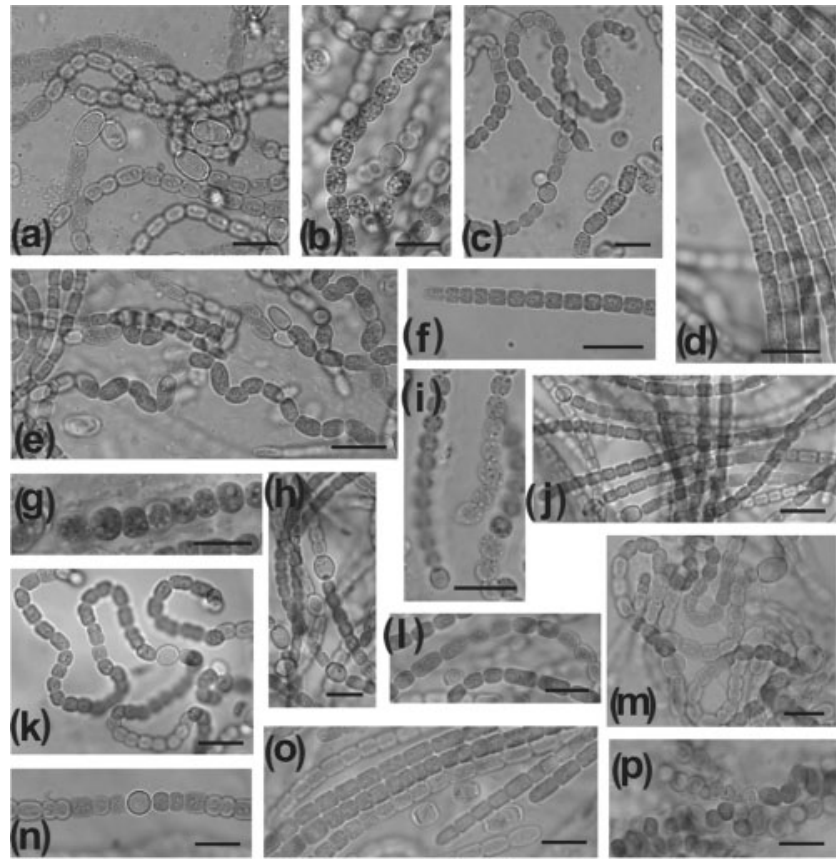

Fig. 2. Light microscope pictures of symbiotic Nostoc strains. (a) Vegetative filaments of Nostoc sp. 8901 :1, symbiont of Gunnera macrophylla. (b) Akinete formation in Nostoc sp. 8964:3, symbiont of Gunnera prorepens. (c) Vegetative filaments and akinetes of $N$. muscorum Lukesova 1/87. (d) Hormogonia with pointed end-cells of Nostoc sp. 8926, symbiont of Gunnera hamiltonii. (e) AKLC of Nostoc sp. 8926. (f) Hormogonium of Nostoc sp. 9104, symbiont of Gunnera tinctoria. (g) Akinete formation of free-living strain Nostoc sp. 996. (h) Vegetative filaments of Nostoc sp. Al1, symbiont of Anthoceros laevis. (i) Akinete formation in the free-living strain Nostoc sp. Cam2SO1. (j, k) Hormogonia and vegetative filaments in Nostoc sp. Al3, symbiont of Anthoceros laevis. (I) Formation of AKLC in Nostoc sp. $\mathrm{Gm}$, symbiont of Gunnera manicata. (m) Vegetative filaments of Nostoc sp. Cr4, symbiont of Cycas revoluta. (n) Nostoc sp. De, symbiont of Dioon edule. (o) Hormogonia formation in Nostoc sp. Cr4, symbiont of Cycas revoluta. (p) AKLC in Nostoc sp. OGU36S02, symbiont of Gunnera tinctoria. Bars, $10 \mu \mathrm{m}$.

However, since the Azolla cyanobionts might actually be incapable of growing under free-living conditions, the observed morphology might represent their stable and sole morphology. A morphological characterization had previously been performed on Azolla cyanobionts (Hill, 1975; Pabby et al., 2003). In all populations examined, only vegetative filaments with elliptic heterocytes were observed (Fig. 3c-e). No akinetes or hormogonia were observed within the cavity at the time of isolation. In the cluster analysis shown in Fig. 1, the separation of Azolla cyanobionts into two branches could be explained by the fact that filaments isolated from Azolla pinnata subsp. pinnata strain 7001 were significantly wider $(8.9 \mu \mathrm{m}$ on average) than those from Azolla rubra strain ADUL2 and from Azolla caroliniana strain 3001 (6.1 and $5.9 \mu \mathrm{m}$ on

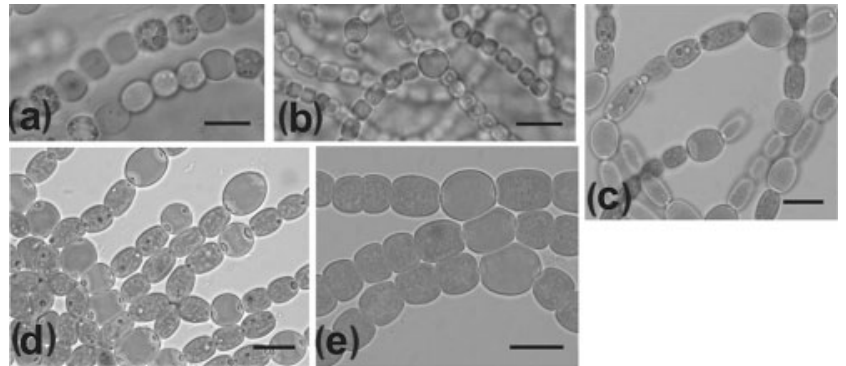

Fig. 3. Light microscope pictures of Azolla cyanobionts and freeliving cyanobacteria. (a) Unusual akinete formation in free-living strain Nostoc sp. TH1SO1. (b) Vegetative filaments of Nostoc sp. TH2S22. (c) Azolla rubra cyanobiont isolate ADUL2. (d) Cyanobiont of Azolla caroliniana, isolate 3001. (e) Azolla pinnata cyanobiont isolate 7001 . Bars, $10 \mu \mathrm{m}$.

average, respectively). However, when considering the other morphological characters, all these isolates were definitely similar. The separation of these isolates in two branches could even be an artefact due to the clustering algorithm, since the Azolla cyanobionts did not fall into any other cluster and were placed at the base of the dendrogram.

\section{Amplified rDNA restriction analysis (ARDRA)}

As a first step to investigate their genetic diversity, 22 Nostoc sp. strains, two Nodularia sp. strains and three cyanobionts of Azolla were subjected to ARDRA applied to the 16S rRNA gene+ITS region. Supplementary Fig. S1, showing the UPGMA cluster analysis of the aligned ARDRA profiles, is available with the online version of this paper. The RFLP of the ITS region alone had been previously demonstrated to discriminate cyanobacterial strains at the intra- or interspecific level (Scheldeman et al., 1999).

Our approach revealed that the cyanobacterial filaments isolated from Azolla shared highly similar ARDRA profiles and formed a branch separated from all other strains studied. Two Nodularia sp. strains clustered in a deep branching group, loosely related to the three free-living Nostoc sp. strains Mau 15, TH3S05 and TH1S01. All the remaining Nostoc sp. strains were part of a unique large cluster with an overall similarity around $62 \%$, inside which three main subgroups could be identified with similarity values ranging between 69 and $76 \%$.

The results indicated a wide variability among Nostoc isolates and only strain De, isolated from the cycad Dioon edule, and the free-living soil isolate Lukesova 1/87 showed $100 \%$ similarity of ARDRA profiles. In all other strains, similarity of ARDRA profiles was lower than $95 \%$. Since ARDRA was not informative enough in resolving the similarity level, the precise relationships among the strains 
were then investigated by analysis of the $16 \mathrm{~S}$ rRNA sequence.

\section{Phylogenetic analysis}

The 16S rRNA gene of 28 Nostoc sp. strains, three cyanobionts of Azolla and two strains of Nodularia was sequenced. The 27 cyanobacterial sequences retrieved from the public domain, listed in Table 1, were added to the phylogenetic analysis. As a whole, this selection of sequences included representatives of the clusters obtained in a phylogenetic analysis of 81 Nostoc strains by Hrouzek et al. (2005) that covered the presently known $16 \mathrm{~S}$ rRNA gene diversity range of soil and symbiotic Nostoc. The phylogenetic trees were built using nearly complete $16 \mathrm{~S}$ rRNA gene sequences longer than $1363 \mathrm{bp}$, apart from the partial sequence of strain Nostoc sp. 996, which was only 905 bp long. NJ, MP and ML trees had nearly identical topologies (data not shown) and the bootstrap values, available for NJ and MP analyses, were largely congruent. This indicated that the phylogenetic relationships among the studied strains inferred from our analysis were largely independent of method-related biases. Therefore, only the NJ tree with the indication of bootstrap values obtained with the NJ and MP approaches is presented in Fig. 4.

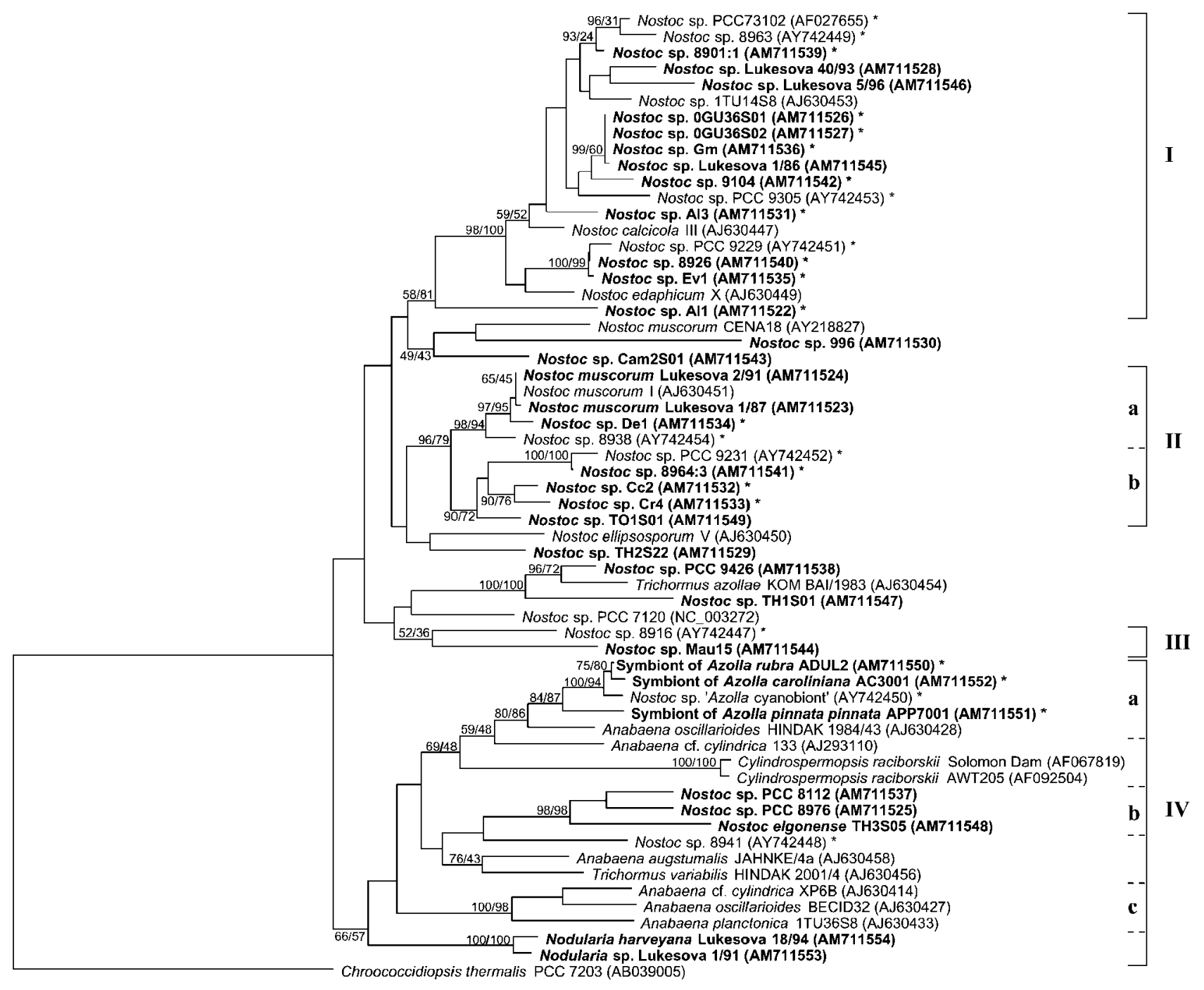

Fig. 4. Neighbour-joining phylogenetic tree based on 16S rRNA gene sequences of heterocystous cyanobacteria, with the indication of retrieved stable clusters. Sequences obtained in this study are indicated in bold. An asterisk indicates sequences from symbiotic cyanobacteria. Numbers at nodes indicate bootstrap values obtained from distance and parsimony analyses, respectively; apart from one cluster discussed in the text, bootstrap values were reported only at nodes where at least one value was higher than $50 \%$. GenBank sequence accession numbers are given in parentheses. 
The smallest clusters of highly similar sequences were all supported by high bootstrap values, indicating that they represented stable monophyletic assemblages of strains. Inferred evolutionary patterns leading to these monophyletic units were sometimes less robust, as indicated by nodes connecting stable clusters, which were not always supported by bootstrapping. At greater evolutionary distance, three larger strain assemblages, supported by relatively high bootstrap values, could also be identified.

A large, rather compact group of 19 strains, indicated as cluster I in Fig. 4, showed bootstrap support of 81-58\%. Apart from Nostoc sp. strain All, a 98-100\% bootstrap value was granted to the group of the remaining 18 strains. This latter, strongly supported group harboured 12 symbiotic strains mainly isolated from Gunnera species, and the four free-living isolates Lukesova 1/86, 40/93, 5/96 and 1TU14S8. Included in this cluster were also N. calcicola III and N. edaphicum X, the morphology of which had been previously described (Hrouzek et al., 2003). The clustering together of N. calcicola and N. edaphicum was supported by the study of Rajaniemi et al. (2005) using $r b c L X, r p o B$ and the 16S rRNA gene as genetic markers. This group also contained Nostoc sp. PCC 73102, the reference strain for DNA-DNA hybridization Nostoc cluster 1 (Lachance, 1981; Rippka \& Herdman, 1992). Clustering of Nostoc sp. PCC 73102 with Gunnera and lichen symbionts has been previously shown in other studies (Svenning et al., 2005; Rikkinen et al., 2002). Nostoc sp. strain All, isolated from Anthoceros laevis, was placed relatively apart in cluster I; it was also distinct from the other members in the cluster analysis of morphological data shown in Fig. 1, where it belonged to branch $\mathrm{A}$, while other cluster members were located in branches B or C. Even if Nostoc sp. strain All formed a separate branch, its contiguity to other cluster I members was shown by all three methods used for the phylogenetic analysis in the present study.

The second supported group (bootstrap values 79-96\%), named cluster II in Fig. 4, contained ten Nostoc sp. strains, six of which originated from symbiotic associations, three from Gunnera and three from cycads, and four free-living strains. Very high bootstrap values supported the existence of two subclusters within cluster II. Subcluster IIa harboured the two $N$. muscorum strains Lukesova $1 / 87$ and 2/91, N. muscorum I and strains De and 8938, isolated from Dioon and Gunnera dentata, respectively. Subcluster IIb contained strains $\mathrm{Cc} 2$ and $\mathrm{Cr} 4$, isolated from Cycas, and strains PCC 9231 and $8964: 3$, isolated from G. dentata and G. prorepens, respectively, together with the free-living strain TO1S01.

Cluster III (Fig. 4), composed of Nostoc sp. strain 8916, from Gunnera monoica, and Nostoc sp. Mau15, a free-living isolate from a rice field, had low bootstrap support (36$52 \%$ ), but was nevertheless considered because it was generated in all three phylogenetic analyses, with a deep branching position in the tree. This deep branching position of strain 8916 was shown by Svenning et al.
(2005), where the strain was linked to Nostoc strains PCC 9231 and 8938. However, by the inclusion of strain Nostoc sp. Mau15 and of more strains related to Nostoc sp. PCC 9231 and 8938, we could demonstrate that Nostoc strains PCC 9231 and 8938 are members of the newly described cluster II, the well-defined group of N. muscorum, while the sequence of strain 8916 fell outside this group and is related to the sequence of strain Mau15.

Reference strain PCC 7120, a typical free-living strain and a representative of Nostoc cluster 3 based on DNA-DNA hybridization (Lachance, 1981), was found to be quite distant from strains of symbiotic origin and located near the root of the large branch including clusters I, II and III.

A large cluster IV (Fig. 4) corresponded to the monophyletic radiation of clusters $1-4$, described in details by Rajaniemi et al. (2005), and included the genera Anabaena, Trichormus, Cylindrospermopsis and Nodularia. On the basis of bootstrap values, several subclusters could be identified inside cluster IV. Strongly supported by bootstrap analysis, subcluster IVa included the sequences retrieved from four cyanobionts of Azolla plants: three sequences were obtained in the present study, while one (GenBank accession no. AY742450) had been previously published by Svenning et al. (2005). Compact clustering of the Azolla cyanobionts is consistently supported by ARDRA of the 16S rRNA gene + ITS and 16S rRNA gene sequence analysis. This is in complete agreement with a large survey of the cyanobionts of 35 strains of all species of Azolla, shown to be very closely related to each other, with a maximal sequence divergence of $2.3 \%$ (Papaefthimiou et al., 2008). In addition, the sequence of Nostoc sp. 'Azolla cyanobiont' (GenBank accession no. AY742450), as well as cyanobiont populations isolated from Azolla pinnata subsp. pinnata 7001, have been included in both that study and the present one. High bootstrap support obtained in all studies confirmed that the cluster containing the four sequences of Azolla cyanobionts represents the cyanobacterial taxon that evolved in the symbiotic association with all species of Azolla. The nearest sequences to the Azolla cyanobionts analysed in this study were Anabaena oscillarioides HINDAK 1984/43 and Anabaena cylindrica 133, isolated from freshwater lakes, in accord with a phylogenetic analysis performed by Papaefthimiou et al. (2008). Trichormus is one of the genera to which the Azolla cyanobionts were assigned in the past (Komárek \& Anagnostidis, 1989; Baker et al., 2003); however, the present study showed that species of Trichormus were unrelated to the Azolla symbionts, which is also in agreement with data obtained by Papaefthimiou et al. (2008). The sequences of the Azolla cyanobionts did not enter any of the Nostoc clusters previously defined by Hrouzek et al. (2005), thus ruling out the possibility that they belong to the genus Nostoc (data not shown). A. oscillarioides HINDAK 1984/43 is consistently connected to Cylindrospermopsis raciborskii in our analysis as well as in the work by Rajaniemi et al. (2005). The same authors described a cluster (cluster 3 ) formed by A. oscillarioides 
HINDAK 1984/43 and A. cf. cylindrica 133, which could well correspond to our subcluster IVa with the inclusion of the less related strain 133 .

The highly stable subcluster IVb held three free-living Nostoc strains of different origins, which were clustered together only on the basis of sequence relatedness; this cluster deserves a complete characterization and possibly the addition of more strains before a supported interpretation is possible.

Sequences in subcluster IVc corresponded to most of the planktonic Anabaena strains included in the study by Rajaniemi et al. (2005), with the addition of some benthic ones, and were not closely connected to any of the new sequences introduced in our study.

Nostoc sp. strain 8941 is the only cyanobiont belonging to cluster IV that did not originate from the Azolla symbiosis; a preferential connection of this strain to any other single or subcluster member of cluster IV is not supported by the phylogenetic analysis. Given that it lacks tightly related companions, the analysis of a larger number of cyanobionts from the Gunnera symbiosis and from other symbioses involving cyanobacteria could give more robust support to the phylogenetic distribution of non-Azolla cyanobionts.

Nostoc strain Cam2S01, N. muscorum CENA 18 (Fiore et al., 2005) and the free-living strain 996 all came from soil or sediments in tropical areas; they were loosely but constantly related in all phylogenetic analyses. A larger number of strains would be necessary to understand whether they represent a new phylogenetic unit. The same is true for Nostoc ellipsosporum V and Nostoc sp. TH2S22, which were always found together and, in MP and ML analysis, also related to the previously cited group of tropical soil strains. Our study included five strains isolated from rice fields in different locations; interestingly, these strains, while coming from habitats where the presence of Azolla is rather common, did not cluster together, nor did they show any appreciable relatedness to cluster IV, where the Azolla cyanobionts were located. This supports the perpetual nature of the Azolla symbiosis, able to exclude all other cyanobacteria living in the nearby environment.

The deepest nodes of the phylogenetic tree, although with only partial support by the bootstrap analyses, separated the 60 sequences in two large clades. A clade that included clusters I, II and III, and is equivalent to cluster 5 of Rajaniemi et al. (2005), corresponded to the typical Nostoc classification, with representatives of the species $N$. muscorum, N. calcicola, N. edaphicum and N. ellipsosporum and strains related to $N$. commune. A life stage with the abundant presence of motile hormogonia is widespread among its members. This large cluster included all nonAzolla-related nostocacean symbiotic isolates, except the Gunnera isolate Nostoc strain 8941. Symbiotic strains (except 8901:1 and Al1) belonging to cluster I contained inside this larger clade showed morphological characters resembling the descriptions of $N$. calcicola and $N$. edaphicum (morphological groups B and C in Fig. 1) previously given by Hrouzek et al. (2005). The compact cluster II had a comparable occurrence of symbiotic strains, with morphological traits mostly resembling those of the species N. muscorum (group A based on morphology, shown in Fig. 1). We suggest that the frequent occurrence of symbiotic strains within clusters I and II could be explained by the intensive production of hormogonia, found in 11 out of 13 cyanobionts and in many free-living strains.

A small cluster of three strains related to Trichormus azollae strain Kom BAI/1983 was found to have a deep rooting inside this large branch with $\mathrm{NJ}$ and ML phylogenies, but not with MP, where it remained as a third independent branch at the initial subdivision of the entire tree (data not shown). Strain Kom BAI/1983, which has been isolated and cultured from Azolla, was in fact definitely unrelated to uncultured, directly isolated filaments of Azolla symbionts. Since the other two strains of this small cluster originated from rice fields, one could suppose that strain Kom BAI/ 1983 was also originally a free-living cyanobacterium in rice fields, isolated by chance from the external surface of the water fern. This would delineate a cluster of these cyanobacteria, even if sequences of other rice field isolates are found in different positions along the tree (Table 1 and Fig. 4). A specifically focussed study on rice field cyanobacterial populations seems to be required to understand the real identity of the T. azollae cluster.

The lowest clade of the phylogenetic tree shown in Fig. 4 corresponded to the wide radiation including the genera Anabaena, Aphanizomenon, Cylindrospermopsis, Nodularia and possibly Anabaenopsis and Cyanospira, discussed in details for the genera Anabaena and Aphanizomenon by Rajaniemi et al. (2005); clusters 1-4 described in that study specifically correspond to this large branch. The directly isolated uncultured Azolla cyanobionts are thus phylogenetically related to the Anabaena radiation while, interestingly, according to literature, Azolla cyanobionts show Nostoc-like apoheterocytic akinete formation (Anagnostidis \& Kómarek, 1988), differing from paraheterocytic akinete formation typically found in species of Anabaena.

The deep branching pattern of the phylogenetic tree indicated that, with only one exceptional case deserving more accurate consideration (strain 8941), two distinct patterns of evolution of the symbiotic behaviour could be hypothesized for the nostocacean cyanobacteria, one leading to symbioses of Nostoc species with a wide variety of plants, the other leading to the association of a unique cyanobacterial type with the water fern Azolla. The former type of association has evolved into a present-day remarkable genetic and morphological diversity of the cyanobionts, coupled with a lack of clear-cut differentiation from freeliving cyanobacterial counterparts, mostly belonging to typical soil species of Nostoc. The latter association, contrastingly, led to the evolution of a compact and homogeneous cluster, separated from the neighbouring 
free-living cyanobacterial genera. This association is particularly strict and selective and up to now it has not been possible to cultivate the cyanobionts separately. What caused the two evolutionary patterns to differentiate remains unclear; however, we can only notice that, while symbioses of Nostoc species involve terrestrial plants, the Azolla symbiosis has evolved in an aquatic environment.

\section{ACKNOWLEDGEMENTS}

We thank gratefully M. C. Margheri for having made cyanobacterial strains of the ISE culture collection available and for critical discussion. C. Sili is thanked for help with microscopy and for critical discussion. D. P. was the recipient of a short-term travel grant to visit S. V.'s lab in the mainframe of the ESF Scientific Programme on Nitrogen Fixing Cyanobacteria - CYANOFIX. Visit exchanges between S.V. and P.H. were supported by a bilateral exchange agreement between the Academy of Sciences of the Czech Republic and the National Research Council of Italy. P.H. was supported by grants MSM 6007665801 (Ecological, evolutionary and experimental biological approaches to the study of the origin and significance of biodiversity) and MSM 6007665808 (Physical biology - New approaches in biological research).

\section{REFERENCES}

Anagnostidis, K. \& Kómarek, J. (1988). Modern approach to the classification system of cyanophytes 3 - Oscillatoriales. Arch Hydrobiol Suppl 80, 327-472.

Baker, J. A., Entsch, B. \& McKay, D. B. (2003). The cyanobiont in an Azolla fern is neither Anabaena nor Nostoc. FEMS Microbiol Lett 229, 43-47.

Caudales, R., Wells, J. M., Antoine, A. D. \& Butterfield, J. E. (1995). Fatty acid composition of symbiotic cyanobacteria from different host plant (Azolla) species: evidence for co-evolution of host and symbiont. Int J Syst Bacteriol 45, 364-370.

Costa, J.-L., Paulsrud, P. \& Lindblad, P. (1999). Cyanobiont diversity within coralloid roots of selected cycad species. FEMS Microbiol Ecol 28, 85-91.

Costa, J. L., Paulsrud, P. \& Lindblad, P. (2001). Genetic diversity of Nostoc symbionts endophytically associated with two bryophyte species. Appl Environ Microbiol 67, 4393-4396.

Fiore, M. de F., Neilan, B. A., Copp, J. N., Rodrigues, J. L. M., Tsai, S. M., Lee, H. \& Trevors, J. T. (2005). Characterization of nitrogenfixing cyanobacteria in the Brazilian Amazon floodplain. Water Res 39, 5017-5026.

Gebhardt, J. S. \& Nierzwicki-Bauer, S. A. (1991). Identification of a common cyanobacterial symbiont associated with Azolla spp. through molecular and morphological characterization of free-living and symbiotic cyanobacteria. Appl Environ Microbiol 57, 2141-2146.

Gordon, D. (2004). Viewing and editing assembled sequences using Consed. In Current Protocols in Bioinformatics, pp. 11.2.1-11.2.43. Edited by A. D. Baxevanis \& D. B. Davison. New York: Wiley.

Guevara, R., Armesto, J. J. \& Caru, M. (2002). Genetic diversity of Nostoc microsymbionts from Gunnera tinctoria revealed by PCRSTRR fingerprinting. Microb Ecol 44, 127-136.

Gugger, M., Lyra, C., Henriksen, P., Couté, A., Humbert, J.-F. \& Sivonen, K. (2002). Phylogenetic comparison of the cyanobacterial genera Anabaena and Aphanizomenon. Int J Syst Evol Microbiol 52, $1867-1880$.
Henson, B. J., Watson, L. E. \& Barnum, S. R. (2002). Molecular differentiation of the heterocystous cyanobacteria, Nostoc and Anabaena, based on complete nifD sequences. Curr Microbiol 45, 161-164.

Henson, B. J., Hesselbrock, S. M., Watson, L. E. \& Barnum, S. R. (2004). Molecular phylogeny of the heterocystous cyanobacteria (subsections IV and V) based on nifD. Int J Syst Evol Microbiol 54, 493-497.

Hill, D. J. (1975). The pattern of development of Anabaena in the Azolla-Anabaena symbiosis. Planta 122, 179-184.

Hrouzek, P., Simek, M. \& Komárek, J. (2003). Nitrogenase activity (acetylene reduction activity) and diversity of six soil Nostoc strains. Arch Hydrobiol Suppl 146, 87-101.

Hrouzek, P., Ventura, S., Lukešová, A., Mugnai, M. A., Turicchia, S. \& Komárek, J. (2005). Diversity of soil Nostoc strains: phylogenetic and phenotypic variability. Arch Hydrobiol Suppl 159, 251-264.

Komárek, J. \& Anagnostidis, K. (1989). Modern approach to the classification system of cyanophytes 4 - Nostocales. Arch Hydrobiol Suppl 82, 247-345.

Lachance, M.-A. (1981). Genetic relatedness of heterocystous cyanobacteria by deoxyribonucleic acid-deoxyribonucleic acid reassociation. Int J Syst Bacteriol 31, 139-147.

Lazaroff, N. (1966). Photoinduction and photoreversal of the Nostocacean developmental cycle. J Phycol 2, 7-17.

Lazaroff, N. \& Vishniac, W. (1961). The effect of light on the developmental cycle of Nostoc muscorum, a filamentous blue-green alga. J Gen Microbiol 25, 365-374.

Lechno-Yossef, S. \& Nierzwicki-Bauer, S. A. (2002). AzollaAnabaena symbiosis. In Cyanobacteria in Symbiosis, pp. 153-178. Edited by A. N. Rai, B. Bergman \& U. Rasmussen. Dordrecht: Kluwer Academic.

Lohtander, K., Oksanen, I. \& Rikkinen, J. (2003). Genetic diversity of green algal and cyanobacterial photobionts in Nephroma (Peltigerales). Lichenologist 35, 325-339.

Ludwig, W., Strunk, O., Westram, R., Richter, L., Meier, H., Yadhukumar, Buchner, A., Lai, T., Steppi, S. \& other authors (2004). ARB: a software environment for sequence data. Nucleic Acids Res 32, 1363-1371.

Mollenhauer, D. (1970). Beiträge zur Kenntnis der Gattung Nostoc. Abh Senckenb Naturf Ges 524, 1-80.

Nilsson, M., Bergman, B. \& Rasmussen, U. (2000). Cyanobacterial diversity in geographically related and distant host plants of the genus Gunnera. Arch Microbiol 173, 97-102.

Pabby, A., Prasanna, R., Nayak, S. \& Singh, P. K. (2003). Physiological characterization of the cultured and freshly isolated endosymbionts from different species of Azolla. Plant Physiol Biochem 41, 73-79.

Papaefthimiou, D., Van Hove, C., Lejeune, A., Rasmussen, U. \& Wilmotte, A. (2008). Diversity and host specificity of genus Azolla cyanobionts. J Phycol (in press).

Peters, G. A. \& Mayne, B. C. (1974). The Azolla, Anabaena azollae relationship. I. Initial characterisation of the association. Plant Physiol 53, 813-819.

Plazinski, J., Zheng, Q., Taylor, R., Croft, L., Rolfe, B. G. \& Gunning, B. E. S. (1990). DNA probes show genetic variation in cyanobacterial symbionts of the Azolla fern and a closer relationship to free-living Nostoc strains than to free-living Anabaena strains. Appl Environ Microbiol 56, 1263-1270.

Rai, A. N., Söderbäck, E. \& Bergman, B. (2000). Tansley review no. 116. Cyanobacterium-plant symbioses. New Phytol 147, 449-481. 
Rai, H., Bergman, B. \& Rasmussen, U. (2002). Cyanobacteria in Symbiosis. Dordrecht: Kluwer Academic.

Rajaniemi, P., Hrouzek, P., Kastovská, K., Willame, R., Rantala, A., Hoffman, L., Komárek, J. \& Sivonen, K. (2005). Phylogenetic and morphological evaluation of the genera Anabaena, Aphanizomenon, Trichormus and Nostoc (Nostocales, Cyanobacteria). Int J Syst Evol Microbiol 55, 11-26.

Rasmussen, U. \& Nilsson, M. (2002). Cyanobacterial diversity and specificity in plant symbioses. In Cyanobacteria in Symbiosis, pp. 313328. Edited by A. N. Rai, B. Bergman \& U. Rasmussen. Dordrecht: Kluwer Academic.

Rasmussen, U. \& Svenning, M. M. (1998). Fingerprinting of cyanobacteria based on PCR with primers derived from short and long tandemly repeated repetitive sequences. Appl Environ Microbiol 64, 265-272.

Rikkinen, J., Oksanen, I. \& Lohtander, K. (2002). Lichen guilds share related cyanobacterial symbionts. Science 297, 357.

Rippka, R. \& Herdman, M. (1992). Catalogue of strains. Pasteur culture collection of cyanobacterial strains in axenic culture. Paris, France: Institute Pasteur.

Rippka, R., Deruelles, J., Waterbury, J. B., Herdman, M. \& Stanier, R. Y. (1979). Generic assignments, strain histories, and properties of pure cultures of cyanobacteria. J Gen Microbiol 111, 1-61.

Rippka, R., Castenholz, R. W. \& Herdman, M. (2001). Subsection IV. (Formerly Nostocales Castenholz 1989b sensu Rippka, Deruelles, Waterbury, Herdman and Stanier 1979). In Bergey's Manual of Systematic Bacteriology, 2nd edn, vol. 1, pp. 562-589. Edited by D. R. Boone, R. W. Castenholz \& G. M. Garrity. New York: Springer.

Scheldeman, P., Baurain, D., Bouhy, R., Scott, M., Mühling, M., Whitton, B. A., Belay, A. \& Wilmotte, A. (1999). Arthrospira ('Spirulina') strains from four continents are resolved into only two clusters, based on amplified ribosomal DNA restriction analysis of the internally transcribed spacer. FEMS Microbiol Lett 172, 213-222.

Strasburger, E. (1884). Die Controversen der indirecten Keimtheilung. Arch Mikrob Anat 23, 301 (in German).

Svenning, M. M., Eriksson, T. \& Rasmussen, U. (2005). Phylogeny of symbiotic cyanobacteria within the genus Nostoc based on $16 \mathrm{~S}$ rDNA sequence analyses. Arch Microbiol 183, 19-26.

Taton, A., Grubisic, S., Brambilla, E., De Wit, R. \& Wilmotte, A. (2003). Cyanobacterial diversity in natural and artificial microbial mats of Lake Fryxell (McMurdo Dry Valleys, Antarctica): a morphological and molecular approach. Appl Environ Microbiol 69, 5157-5169.

Tomaselli, L., Margheri, M. C., Giovannetti, L., Sili, C. \& Carlozzi, P. (1988). The taxonomy of Azolla spp. cyanobionts. Ann Microbiol 38, $157-161$.

Vagnoli, L., Margheri, M. C., Allotta, G. \& Materassi, R. (1992). Morphological and physiological properties of symbiotic cyanobacteria. New Phytol 120, 243-249.

van Hove, C. \& Lejeune, A. (2002). Applied aspects of AzollaAnabaena symbiosis. In Cyanobacteria in Symbiosis, pp. 179-193. Edited by A. N. Rai, B. Bergman \& U. Rasmussen. Dordrecht: Kluwer Academic.

West, N. J. \& Adams, D. G. (1997). Phenotypic and genotypic comparison of symbiotic and free-living cyanobacteria. Appl Environ Microbiol 63, 4479-4484.

Zheng, W. W., Nilsson, M., Bergman, B. \& Rasmussen, U. (1999). Genetic diversity and classification of cyanobacteria in different Azolla species by the use of PCR fingerprinting. Theor Appl Genet 99, 1187-1193.

Zheng, W., Song, T., Bao, X., Bergman, B. \& Rasmussen, U. (2002). High cyanobacterial diversity in coralloid roots of cycads revealed by PCR fingerprinting. FEMS Microbiol Ecol 40, 215-222. 